its effects; whether we have operated successfully or otherwise - whether what we have just done is sufficient, or whether the other eye should be operated on. I therefore never administer it without first apprising my patient of the possibility of a second operation being required. If we could always be sure that the strabismus was either single or douhle, we might pronounce a positive prognosis; but, in the uncertainty which often exists on this point, it will save disappointment to the patient and our own credit to give the warning just referred to. Another serious objection to chloroform is its liability to produce sickness, which both renders the operation more tedious and the hæmorrbage more considerable. I have seen so much blood poured out during the straining efforts to vonit, as to raise visibly the conjunctiva from the sclerotic, and to leave the eye discoloured for upwards of six weeks afterwards.

In conclusion, I would observe that the object of this and of the preceding papers was threefold:-

1. To call attention to the existence of a feeling, widely diffused among the profession, inimical to operative measures for the cure of strabismus.

2. To show that this feeling originated in the frequent occurrence of failures, whence the operation has acquired the character of being an uncertain one.

3. To point out the several causes of failure. Without a knowledge of these, it is a mere lottery whether success or failure shall result. With this knowledge, any surgeon possessing sufficient manipulative skill, may perform the operation with certainty and success.

\section{PORT WINE ENEMATA AS A SUBSTITUTE FOR TRANSFUSION OF BLOOD IN CASES OF POST PARTUM H AMORRHAGE.}

By H. Llewellyn Williams, M.D.Edin., St. Leonard's-on,Sea ; late Physician to the Dispensary and Maternity Charity, Beverley.

ON September 22nd, 1856, I was called into the country, a dis. tance of four miles, to attend Mrs. C., aged 42 , then about to be confined of her tenth child. All her previous accouchements had been favourable. When about six months advanced in pregnancy, she received a violent shook by the sudden death of her youngest child, since which time her general health had become much impaired. She had a peculiar pasty anæmic appearance, and complained much of general weakness.

On my arrival, I discovered the os uteri fully dilated; the membranes ruptured spontaneously; and, after three or four powerful pains, a fine female child was born. Placing my hand on the fundus uteri, I felt it slowly contracting under my grasp. My patient exclaimed, "I am flooding away," and fainted. I immediately had recourse to such restoratives as were at hand, and presently she began to revive. On making an examination, I found the placenta lying detached in the vagina, and removed it without difficulty, together with a large quantity of coagula. I had administered a dose of volatile tincture of ergot. The uterus continuing to contract feebly, and more than the usual amount of discharge being present, I ap plied some cold cloths to the vulva and lyypogastrie region; this having little apparent' effect in arresting the discharge, though steady pressure was continuously applied with the hand on the abdomen, I had recourse to the plan recommended by Gooch, of throwing a quantity of cold water suddenly on the abdomen. My efforts still being foiled, and the hæmorrhage continuing, the powers of life manifesting evident symptoms of flagging, introduced my left hand into the uterus, after the manner: also recommended by Gooch, endeavouring to compress the bleeding vessels with the knuckles of this hand, whilst with the other I pressed upon the uterine tumour from without. This combination of external and internal pressure was equally as unavailing as any of the other plans already tried. At last, by compressing the abdominal aorta, as recommended by Baudelocque the younger (Mémoires de l'Académie des Sciences, Jan. 1835), I was enabled effectually to restrain any further hæmorrhage. The condition of my patient had now become sufficiently alarming, she having been for apwards of half an hour quite pulseless at the wrist, the extremities cold, continual jactitation being present, the sphincters relaxed, and the whole surface bedewed with a cold clammy perspiration. It now became a question what remedy could be had recourse to, which. should rescue the patient from this alarming state, it being utterly impossible to administer any stimulant by the mouth. My distance from home; together with considerable .739 objections to the operation itself, which it is not here needful to dwell upon; made me abandon the idea of transfusion of blood; but, as a means which I believe will prove equally as powerful as transfusion in arresting the vital spirit, I had recourse to enemata of port wine, believing that this remedy possesses a threefold advantage. The stimulating and lifesustaining effects of the wine are made manifest in the system generally; the application of cold to the rectum excites the reflex action of the nerves supplying the uterus; and the astringent property of port wine may act beneficially by causing the open extremities of the vessels themselves to contract.

I commenced by administering about four ounces of port wine, together with twenty drops of tincture of opium. It was interesting to note the rapidity with which the stimulating effects of the wine became manifest on the system. Two minutes after the administration of the first enema, there was a slight pulsation distinguishable in the radial artery, which perceptibly increased in strength for the space of five minutes, after which the pulse again began to flag, and I had recourse to the administration of a second enema twenty minutes after the first. A more marked improvement was now manifest in the patient. She regained her consciousness: the pulse continued feebly perceptible at the wrist. In half an hour, I had again recourse to the enema, with the most gratifying result and, after ten hours most anxious watching, I had the happiness of leaving my patient out of danger. The quantity of wine consumed was rather more than an ordinary bottle.

Pressure of business and subsequent ill health have hitherto prevented me giving the foregoing case to the profession. I hope it may now be perused with interest.

\section{CASE OF OSTEO-SARCOMA.}

\section{By Charles Hallett, Esq., Axminster.}

Fanny Cook, aged 21 years, died under my care on June 21st, 1857. She was of a scrofulous habit, with light hair and complexion; and her mother informed me that she had been unhealthy from childhood. At about the age of 10 years, she had an enlargement of the abdomen, no doubt from disease of the mesenteric glands. At the age of 16, menstruation commenced, and the swelling gradually subsided; but from that time she was subject to severe pains in the upper part of the thigh on any unusual exertion, and she had several attacks of acute rheumatism.

She came under my care in September 1856, for aoute rheumatism. She was at that time working in a silk-factory. She recovered from the attack in about four weeks, and resumed her work, but only for a few days. She now complained of a violent pain in the right hip; and, in about a week, it extended to the upper third of the thigh. The pain continued excessive, with tenderness and swelling of the parts; the pulse was seldom less than 100 , often 120 ; the tongue dry, and skin hot, with frequent rigors. I considered it to be a case of inflammation of the periosteum, and treated it accordingly; but the disease gradually advanced, and the tension became so great, with indistinct fluctuation, that I divided the fascia freely, supposing there might be some confined matter; but the discharge was small, and very little relief was afforded. She now had oocasional convulsive tits; and the pain was only relieved, so as to allow her a little sleep, by very powerful opiates. She said "the pain was all in the bone"; and I was of opinion that it was extensively diseased, and, from the progress of the case, supposed it to be osteo-sarcoma, and stated my opinion to her friends.

I was allowed to examine the parts after death, and found the circumference of the right thigh at the largest part to be twenty-six inches; that of the left thigh at the same part was only eight inches. The tumour extended from the hip to within six inches of the knee, and was of an ovoid shape. The skin was tense and shining as far as the tumour extended, and appeared ready to burst at several places; it showed a tendency to point at about three inches below Poupart's ligament, on the outer side. On being cut into, it had much the appearance of brain, and was intersected by fibrous bands; and had, for the most part, the feel and hardness of scirrhous liver; but it. was softened in some parts, and contained pus ; and osseous matter was intermixed, so that, when the tumour was cut, a grating sound was produced that conld be heard at some distance. The head and shaft of the femur, to within six inches of the knee; were almost destroyed, except $a$ thin plate of bone, full of holes, and giving way to a slight pressure of the knife, but only extending through about balf the length of the tumour; and be- 
neath it was a large quantity of pus. Not the restige of a muscle was to be seen in any part of the thigh; and the great ressels and nerves appeared like mere cords, and were only present at intervals, and could not be traced.

\section{ON THE PHYSICAL CAUSES OF HYSTERIA.}

By DAYin Nerson, M.D.Edin.; formerly Physician to the Queen's Hospital, and Professor of Clinical Medicine in Queen's College, Birmingham.

Tine innumerable protean forms assumed by the strange group of diseases called hysteria, have rendered it one of the most defiant to all medical treatment. Certainly, the very name indicates that the more ancient authors recognised its origination in some disorder of the uterine functions; but, at the same time, such conclusion was rather drawn from the general fact that it was peculiar to women, than from any satisfactory investigation into the actual condition of organs which at those earlier periods were little known or understood. The advance of time, however, has always tended to narrow the list of diseases attributable to mere functional disorder, and to trace such disordered functions to physical causes more or less apparent.

Without doubting-for who could doubt?-the potent in. fluences exercised over bodily functions by mental emotion alone, which is invisible and intangible in its very nature, we yet cannot close our eyes to the fact that many deviations from health, which formerly were referred, in a very vague manner, to hysterical excitement-cachexy, idiopathic debility, and the like-are now found to depend upon physical causes, palpable, visible, and demonstrable. Witness the explication of such diseases as scurvy, aræmia, gout, and rheumatism, and the cardiac, renal, hepatic, and pulmonary dropsies-all formerly attributed to cachexy, but now traced each to its own peculiar origin, whether such origin be chemical deficiencies or redundancies in the blood, or anatomical changes of structure and deposit.

'The knife of the morbid anatomist and the microscope-but, above all, the advances of chemical science-have been the main agencies in the philosophical elucidation of causes, formerly known only in their effects; but, besides such helps, we have also been greatly aided by those closer habits of investigation and reasoning that have characterised an era of which Bacon, Harvey, Sydenham, Newton, Lavoisier, Hunter, Alison, etc., have been the models. The whole tendency of such men's efforts has been to disperse unbased theories to the winds, and to ground whatever doctrines they advanced upon a series of facts clearly ascertained and capable of demonstration. Following this inductive method, I think I have observed some very minute physical causes giving rise to hysterical affections the most severe and alarming; and, under the belief that too little pains have generally been taken to unravel the reflex nervous actions constituting such disease, and too much readiness exhibited to dismiss all further thought on the matter by the trite expression "It is merely hysterical", I have adventured to draw the attention of the profession to a few points, trusting that they may move others to further in. quiry and cbservation in the same direction.

Admitting, as I have already done, the close connection of the emotional centres with the ganglionic and other nervous expansions that invest the reproductive system through the medium of the spinal cord, I yet believe that hysterical disorders spring less from any idiopathic irritability of such emotional centres than from morbid physical irritation at the periphery of the nerves. This view is strengthened by the consideration that it is not so much women of a delicate mental organisation, if such be coupled with good bodily health, that are most subject to hysteria; but rather such as are diseased, and especially if such disease affect those organs that are most intimately associated with such emotional functions. In short, the emotional and nervous excitement which occurs, is, for the most part, a reflection from the local disorder, rather than is the local disorder consequent upon primary emotion; just as some flashing fancy of being buried alive, or covered with vermin, or otherwise tickled or irritated, may produce an emotional sense of constriction at the chest, or a fit of fidgets, or a shudder, or a feeling of superficial itching; while the actual subjection to the outward realities themselves must give rise both to the emotional and muscular excitation: so is it to my mind with cases of hysteria. I believe that a case may now and then occur wherein the fits may be traced to emotion alone; but that the vast majority are due to sub. stantial causes. The first I should view as a partial mental derangement; the second, as the real bodily idisease; and, even if I could not discover any organic peripheral disorder, I should not be the less convinced of its existence, unless I could discern by direct or collateral evidence that there was morbid processes going on within the brain and spinal prolongation.

To illustrate my meaning practically, I shall now adduce some cases that have occurred amongst many others of a similar kind in my practice during the last few years; and, not to tire my brethren with long details of dates and changes in the symptoms, having little reference to the special point at issue, $I$ shall merely give the salient facts, embracing the symptoms, the principles of treatment, and the results.

Case I. Mrs. J., aged about 33, had had no children. Sne had complained of general derangement of health for several years, and had become of late much reduced, being preternaturally thin and pale, and having a haggard worn-out expression. Her special ailments, however, consisted of an excessive leucorrhœa, the discharge approaching to the appearance of pus, great frequency of micturition, lancinating pains on passing the urine, extreme tenderness about the seat of disease, which had led to some domestic unhappiness, and severe attacks of the hysteric paroxysm, especially at the menstrual periods. All these symptoms proved to be dependent on the existence of a few very minute erectile and sensitive papillæ in the neighbourhood of the urethra and outlet of the vagina. The latter looked like caruncula myrtiformes, highly charged with vascular and nervous matter. After using the routine remedies of steel and valerian, and having soothing unguents and nitrate of silver applied in vain, I recommended the surgical removal of those minute growths. From their exquisite sensibility, the pain inflicted was sharp, but momentary; and from that period her distress has left her. She has become plump and well coloured, and is able to manage her father's business with ease.

I may just add, as a suggestive hint, that I was subsequently called into consultation regarding her mother, who was in the last stage of cancer of the womb, and who died two days or so after I had seen her. The father then stated that, in earlier life, she had suffered in a manner similar to her daughter; but that she would never consent to see any medical man upon the subject, until fearful floodings set in, and the case was hopeless.

CASE II. Mrs. M. H., aged 52, having had no children, had ceased to menstrunte for four years; but of late had been subjected to attacks of flooding, which had blanched her cheeks, and reduced her in flesh. Since these losses of blood, she had become very nervous and excitable, trembled from the slightest cause, was unable to sleep soundly, and had had frequent attacks of acute hysteria, which she had never been subject to before. There were enlargement and descent of a flabby uterus, and round the edges of the os, which was very sensitive and red, there was a roughness, as of grains of sand, with patches of hard substance about the size of a split pea here and there. She was put under the tinctures of steel and of ergot, with muriate of morphia, and nitrate of silver was ordered to be applied to the cervix, and to the inner surface of the uterus. Under this treatment the hæmorrhage was arrested, and all the other symptoms along with the fits vanished.

Case IIr. Mrs. P., aged about 30, had had some children, who had all died, and several miscarriages. She had, for a considerable time, been the subject of severe monthly hæmorrhages, and in the intervals there had been troublesome dysuria, much tenderness, and a profuse discharge of thick pus per vaginam. Under these circumstances she had become thin, and her complexion changed to a yellowish straw colour. At the same time she grew more than usually hysterical; she could scarcely speak without crying, and the slightest contradiction or excitement brought on the actual paroxysm. She seemed to have gone from one practitioner to another, principally to those engaged in one special walk, for reasons sufficiently obvious; but it was observed that the treatment adopted by each one was almost a repetition of that of the others, and she continued the same. The cause was evidently something out of the usual course, and was found to consist in the presence of a surprising number of polypoid growths on the rnucous surface, of different sizes, some having narrow necks, and others springing from broad bases. The cervix was also deeply ulcerated. The advice was, that she should have the growths removed by means of scissors, and the cervix treated with nitrate of silver. After this was done, 